\title{
The Implementation of Learning Together in Improving Students' Mathematical Performance
}

\section{Hobri}

Dr., Head, Department of Post-Graduate Mathematics Education, Faculty of Teacher Training and Education, University of Jember, Jember, Indonesia, hobri1973@gmail.com

\section{Dafik}

Prof., Dean, Faculty of Teacher Training and Education, University of Jember, Jember, Indonesia,d.dafik@gmail.com

\section{Anowar Hossain}

Dr. Md., corresponding author, Visiting Researcher, Faculty of Teacher Training and Education, University of Jember, Jember, Indonesia, \& Director, Natore Institute of Education and Research, Natore, Bangladesh, anowar_24434@yahoo.com

$$
\begin{aligned}
& \text { This research study investigated the effects of Learning Together model of group } \\
& \text { learning on students' mathematics achievement and attitudes toward mathematics, } \\
& \text { and identified teachers' perception on the implementation of Learning Together in } \\
& \text { secondary mathematics classrooms in Natore, Bangladesh. The mood of } \\
& \text { triangulation, a combination of quantitative and qualitative methods for data } \\
& \text { collection and data analysis, was employed in the study. Data were collected using } \\
& \text { students' mathematics achievement test, attitudes toward mathematics } \\
& \text { questionnaire and teachers' interview. The independent-sample t-test was used to } \\
& \text { analyse the quantitative data while the content analysis was used to analyse the } \\
& \text { qualitative data. The results showed that the effects of Learning Together on } \\
& \text { students' mathematics achievement and attitudes toward mathematics were } \\
& \text { significant, and the teachers' perception on the implementation of Learning } \\
& \text { Together was positive. The findings revealed that Learning Together model } \\
& \text { contributed to the development of students' mathematical performance due to } \\
& \text { proper formation of groups, group members' cooperation to each other's learning } \\
& \text { and their sincerity to teachers' incentives during the treatment period. }
\end{aligned}
$$

Keywords: Learning Together model, triangulation, mathematics achievement, attitudes toward mathematics, learning

Citation: Hobri, Dafik, \& Hossain, A. (2018). The Implementation of Learning Together in Improving Students' Mathematical Performance. International Journal of Instruction, 11(2), 483-496. https://doi.org/10.12973/iji.2018.11233a 


\section{INTRODUCTION}

Learning Together model of group learning is well documented as an effective teaching and learning method in mathematics education at primary, secondary and tertiary levels. The term group learning is widely known as cooperative learning that refers to working together in small groups to achieve a common goal. According to Johnson and Johnson (1994), group learning is an instructional method in which students are grouped in small learning teams and work in cooperation with each other to perform a task presented by the teacher. Group learning is a mood of learning in which students of different levels of ability work together in small groups to reach a common goal, that is, all will go together and nobody will be behind. Group learning is a Learning Together to help each other, share with each other and facilitate each other's learning to achieve a shared goal. Johnson and Johnson indicate that Learning Together requires elements of positive interdependence, individual accountability, face-to-face interaction, appropriate use of group skills and group processing to achieve the best group results by means of mutual assistance among the group members. All the members of the group must work on the task assigned by the teacher and each is aware that the success or failure of each individual will affect the result of the whole group. Rimmerman (2004) referred to Johnson and Johnson's work as the modern era of group learning. Their model of group learning is known as Learning Together can be applied to any discipline and grade level.

In Bangladesh, secondary school certificate (SSC) is the first major public examination faced by the students after completion of two years of secondary education. The SSC is an indicator of the quality of secondary education but no students from 24 schools passed in SSC examination in 2014 (BISE, 2014) and in which most of them failed in mathematics. This failure rate indicates deficiency in teaching of mathematics. According to Hossain et al. (2013), to minimize the failing rate in SSC examination, teachers should find ways to enhance students' learning. In their study they found group learning is effective in teaching and learning mathematics. Samad (2005) reported based on a sample of Bangladesh secondary students' mathematical performance that teachers are familiar with conventional mode of thought and teaching; teachers' teaching strategies based on their individual creativity. He commented that this traditional teaching strategy has negative impact in students' performance in SSC examination. $\mathrm{He}$ stresses the need of involvement of secondary teachers with those methods of teaching which have positive impact in students' academic performance.

There are many methods of teaching and learning, of them, group learning is important because group learning has been a subject of interest to many researchers and at the secondary school level, there is a substantial body of literature supporting the idea that students can attain higher achievement, especially in mathematics, through Learning Together in groups. Zakaria et al. (2010) embarked on a study to determine the effects of group learning on students' mathematics achievement and attitudes toward mathematics. They found that group learning improved students' mathematics achievement and attitudes toward mathematics. They concluded that group leaning improved students' performance in mathematics and teachers in educational institutions who teach mathematics need to be aware of the importance of group learning and thus 
changing the practice of conventional teaching method to group learning method. Similarly, Alabekee et al. (2015) examined the effects of group learning on students' achievement in mathematics. They found that the performance of experimental students of group learning was better than the conventional students of traditional way of teaching in improving their achievement in mathematics. Likewise, Tran (2013) investigated the effects of group learning on students' mathematics achievement and attitudes toward mathematics in secondary level and found that group learning had a positive effect in developing students' achievement in mathematics and promoting their attitudes toward mathematics. Ozsoy and Yildiz (2004) among others conducted an experimental research on the use of group learning in mathematics. They investigated the effects of Learning Together, a group learning strategy, on mathematics achievement. In the study, the control group received traditional mathematics instruction, while the experimental group received mathematics instruction using Learning Together model of group learning. The researcher used the pre-test and posttest design and compares mean scores. Results revealed a significant difference in favour of the Learning Together of group learning techniques. Gubbad (2010) carried out a study on the implementation of group learning in mathematics classrooms. The students were divided randomly into two groups. The experimental group students were taught using group learning model while the control group students were taught using lecture method. The findings revealed the group learning model had a significant effect on mathematics achievement. Gokkurt et al. (2012), in their experimental study, compared the effects of Learning Together model with traditional teaching method on students' mathematics achievement in secondary level and they found that Learning Together students outperformed the traditional teaching students on their performance in mathematics. Other studies had similar findings that group learning has produced positive effects on mathematics achievement and attitudes toward mathematics reported by Barbato (2000), Effandi (2003) and Martin (2005). Hence this research study aimed at identifying the effects of Learning Together model of group learning on students' mathematics achievement and attitudes toward mathematics, and investigating teachers' perception on the implementation of Learning Together in selected secondary schools in Natore, Bangladesh. The objectives of this study were:

1. To examine the effects of Learning Together on students' mathematics achievement.

2. To identify the effects of Learning Together on students' attitudes toward mathematics.

3. To identify the teachers' perception on the implementation of Learning Together.

\section{Importance of the Study}

The important parts of this research study are as follows:

1. In this research study the experimental students are taught using Learning Together model and it is found that Learning Together contributes to the improvement of students' mathematics achievement and attitudes toward mathematics. 
2. This research study identifies that better students help their weaker group mates in the Learning Together environment to solve their mathematical problems in the aim of achieving shared performance in mathematics.

3. In this research study the experimental teachers implement Learning Together in their teaching instruction upon observing students' better performance in mathematics.

4. This research study is a contribution to secondary schools for promoting students' mathematical performance in SSC examination.

5. This research study suggests teacher education institutions to include Learning Together as a part of their curriculum content.

6. This research study encourages future studies on the importance of implementing Learning Together model in primary, secondary and tertiary levels by looking closer at the students' mathematical performance and teachers' perception in this study.

\section{METHOD}

\section{Research Design}

To examine the effects of Learning Together of group learning on students' mathematics achievement and attitudes toward mathematics, and to identify the teachers' perception on the implementation of Learning Together, the researcher conducted this research study in selected secondary schools in Natore, Bangladesh. The research study employed both the quantitative and qualitative methods for data collection and data analysis. To obtain the research objectives, the researcher utilized the mode of triangulation. Social science researchers like Miles and Huberman (1994), and Sechrest and Sidani (1995) have supported the combination of quantitative and qualitative data collection techniques in conducting research, and noted that both could be complement and supplement each other. Cohen et al. (2002) also emphasize the advantages of triangulation by stating that triangular techniques attempt to explain more fully the richness and complexity of human behaviour by making use of both quantitative and qualitative data.

To obtain the three research objectives, the research study was conducted into two parts: (i) quantitative research method and (ii) qualitative research method. In the first part, the quantitative research method used was a quasi-experimental design. The quantitative research method was used to obtain the first two research objectives.

The second part of the study focused on the qualitative research method that involved interviewing the mathematics teachers. The qualitative research method was used to address the third research objective.

To investigate the effects of Learning Together model of group learning in comparison to conventional teaching, the study employed a quasi-experimental 'Equivalent control group with pre-test and post-test' (Berg \& Latin, 1994; Campbell \& Stanley, 1963) design. The equivalent control group refers to the elements that no characteristics 
between two groups had a different expected value. Prior to the experimental treatment, two groups should be similar in every respect. An initial observation (e.g., a pre-test) can confirm that the two groups are at least similar in terms of the dependent variables under investigation. If, after one group has received the experimental treatment, we then find group differences with respect to the dependent variable, we might reasonably conclude that the post-treatment differences probably the result of that treatment (Leedy \& Ormrod, 2001). In this study, the preliminary pre-test was conducted on students' mathematics achievement and attitudes toward mathematics in both the control and experimental groups, and the results illustrated that both groups were equivalent in terms of the students' mathematics achievement and attitudes toward mathematics prior to the treatment. In addition, the participants for both groups were equal at the pre-treatment stage, their performance in both experimental and control groups were equivalent and they started out equal before the treatment strategy was given.

The quasi-experimental design compared a control group of conventional teaching method with an experimental group using group learning based on the Learning Together model of Johnson and Johnson (1994). Learning Together is a group learning strategy developed by Johnson and Johnson (1994) to improve students' mathematics achievement and attitudes toward mathematics. The Learning Together model consists of five elements are as follows:

1. Positive interdependence: All members in a group cannot succeed unless everyone succeeds, ie, group members are interdependent on each other's learning and the success of an individual member is the success of other members of the group.

2. Individual accountability: Group members are accountable for achieving their shared goal and each member is responsible toward contributing his or her share of work in the group.

3. Face-to-face interaction: Group members should continue help, share, encourage and support each other's efforts to reach a common goal.

4. Interpersonal and small-group skills: Group members should be aware of interpersonal and small-group skills such as leadership, decision making and trust building for communication and managing conflict among group members for the benefit of greater success.

5. Group processing: Group members should act upon group processing to check their degree of success and reflect how well the group is functioning to reach a common aim. Every group member should acknowledge each other's effort in the group activities to achieve a shared goal.

Students in the experimental group were taught the mathematical contents using these five elements as guidelines under the Learning Together treatment while students in the control group were taught the same mathematical contents using conventional teaching method during the study. Table 1 shows a quasi-experimental design and Figure 1 shows the mode of triangulation. In Table 1, A represented the experimental group while $\mathrm{B}$ represented the control group. $\mathrm{O}_{1}$ represented the pre-test while the post-test 
was represented as $\mathrm{O}_{2}$ for the experimental and control groups respectively. The Learning Together treatment was represented as X.

Table 1

Equivalent pre-test and post-test control group design

\begin{tabular}{llll}
\hline Group & Pre-test & Treatment & Post-test \\
\hline $\begin{array}{l}\text { A } \\
(\mathrm{n}=56)\end{array}$ & $\mathrm{O}_{1}$ & $\mathrm{X}$ & $\mathrm{O}_{2}$ \\
$\mathrm{~B}$ & & - & \\
$(\mathrm{n}=56)$ & $\mathrm{O}_{1}$ & - & $\mathrm{O}_{2}$ \\
\hline
\end{tabular}

To identify the mathematics teachers' perception on the implementation of Learning Together of group learning in the mathematics classrooms, the researcher conducted interview with the experimental teachers. Figure 1 shows the mode of triangulation where qualitative data were triangulated with quantitative data to find out the effects of Learning Together on students' mathematical performance.

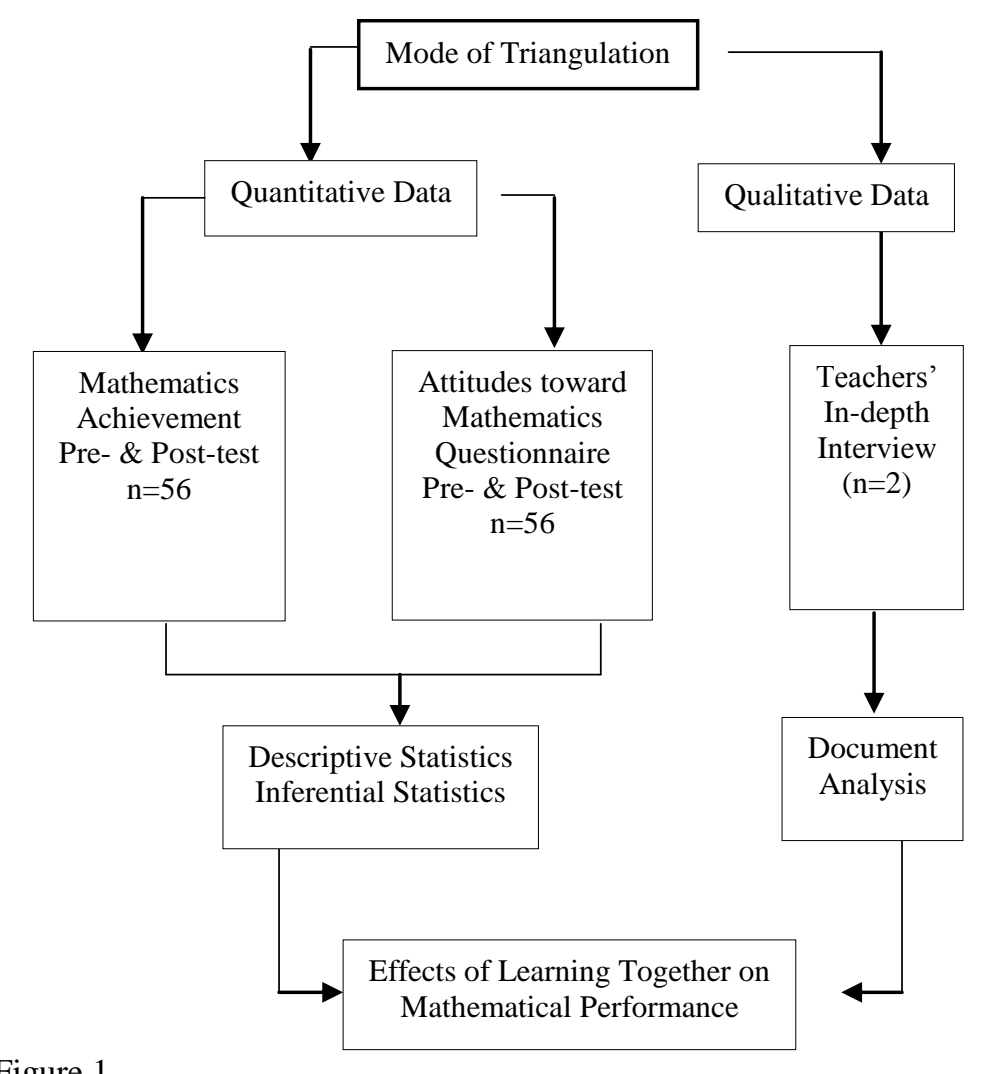

Figure 1

Mode of triangulation 


\section{Participants}

The participants under this research study were the Grade 9th students of selected secondary schools in Natore, Bangladesh. Prior to implementation of the study, the researcher obtained permission from the District Education Officer of Government of the People's Republic of Bangladesh for conducting this study. Dharabarisha High School and Sher-e-Bangla High School were randomly selected and approved by the District Education Officer to carry out this study. A total of 112 full-time students from 2 secondary schools constituted the sample, of them, 56 students for experimental group and the other 56 students for control group were randomly selected. Out of the 56 experimental group students, 29 were male and 27 female students. Of the control group students, 30 were male and 26 female students. In sum, there were 59 male and 53 female students who made up the total of 112 students participated in the study. Each experimental school comprised two sections in which Section-I was represented as the experimental group while Section-II represented the control group in Grade-9 mathematics classrooms as per the directives of the Headmasters of the sample schools. The duration of this study was five months from $1^{\text {st }}$ of January to $31^{\text {st }}$ of May 2015.

\section{Instruments}

The instruments used in this study were students' mathematics achievement test, attitudes toward mathematics questionnaire and teachers' interview.

Participants were taught the contents of mathematics curriculum, which was selected from the secondary mathematics textbook, such as algebraic expression consisting of unit 3.1, 3.2, 3.3, 3.4 and 3.5; geometric theorem of unit 6 and 7; trigonometric ratio of unit 9.1 and 9.2 during the treatment period. Students' mathematics achievement test was designed following the mathematical contents taught in the experiment. The students' mathematics achievement test is divided into two parts: part A and part B. Part A is concerned with demographic data of the participants namely gender and serial number while Part B solicited the students' mathematics achievement test comprising a 10 -item of open-ended questions.

The researcher employed a 20-item questionnaire adapted by Fennema and Sherman (1976) to measure students' attitudes toward mathematics. The students' attitudes toward mathematics questionnaire are also divided into two parts: part A and part B. Part A is concerned with demographic data of the respondents namely gender and serial number. Part B solicited the students' attitudes toward mathematics questionnaire. A full-scale of 20-item questionnaire were designed on a 5-point Likert scale, with $1=$ strongly disagree, $2=$ disagree, $3=$ undecided, $4=$ agree and $5=$ strongly agree.

Content validity for the instruments, ie, students' mathematics achievement test, students' attitudes toward mathematics questionnaire and teachers' interview were determined through the consensus of the experts in the relevant field. The instruments used in this study were content validated by a professor of mathematics, University of Dhaka and a professor of mathematics, University of Rajshahi. These instruments were pilot tested to suit the objectives of the study. A few changes made in the questions following the experts' remarks and finally these instruments were set for the formal 
study after the approval of District Education Officer with the Government of Bangladesh.

The reliability of mathematics achievement test was calculated by using KuderRichardson 20 formula. The K-R 20 reliability coefficient of mathematics achievement test was .73 . The reliability of the items in the students' attitudes toward mathematics questionnaire was determined by computing the Cronbach's Alpha reliability index. The item analysis was also carried out to measure the correlation coefficient of all the items. The Cronbach's Alpha reliability coefficient of the students' attitudes toward mathematics questionnaire was .81 .

\section{Data Collection and Data Analysis}

The students in both the experimental and control groups completed the pre-test and post-test of students' mathematics achievement and attitudes toward mathematics. These quantitative data were coded using statistical software SPSS. These quantitative data were treated as interval scale in this research. As for qualitative data, the researcher conducted semi-structured interview with 2 experimental teachers (T1 \& T2) in the form of verbatim transcript.

Descriptive and inferential statistics were used to analyse the quantitative data while content analysis was employed to analyse the qualitative data. Demographic information of the participants such as frequency, mean and standard deviation were summarized using descriptive statistics. And to test the hypothesis, inferential statistics, ie, independent-sample t-test was administered. Since the participants in control group were of different individuals with those of the experimental group, the data was independent, therefore, the independent-samples t-test was done to find out the effects of Learning Together on students' mathematics achievement and attitudes toward mathematics between experimental and control groups (Hinton et al., 2004). The independent-sample t-test was used to compare the mean scores of two groups to find out any significant difference at .05 alpha level.

\section{FINDINGS}

The results are reported in light of the objectives of this research study as mentioned earlier. To examine the effects of Learning Together of group learning on students' mathematics achievement, independent-sample t-test was used to analyse pre-test and post-test mean scores of students in experimental and control groups. The preliminary assumption of the independent-sample t-test was determined through checking the normality of data. The students' mathematics achievement pre-test and post-test scores were recorded for each of the 112 students. The distribution of pre-test had skewness of .05 and for post-test skewness of .03 . Since the skewness was between -1 and +1 , the distribution was normal (Morgan et al., 2001). The second check for normality that skewness divided by standard error of skewness should be between negative two and positive two (SPSS, 1999). Skewness of pre-test and post-test divided by its standard error was .22 and .14 confirmed the normality. As depicted in Table 2, the pre-test mean score for the experimental group was $10.98(\mathrm{SD}=.70)$ and that of control group was $10.94(\mathrm{SD}=.72)$. The difference between mathematics achievement pre-test mean 
scores of two groups $[\mathrm{t}(110)=.26, \mathrm{p}>.05]$ is not significant at .05 alpha level. This suggests that performance of both groups were equivalent at the start of this study.

Table 2

Students' mathematics achievement pre-test mean scores between experimental and control groups are compared using independent-sample test

\begin{tabular}{lllllll}
\hline Group & $\mathrm{n}$ & Mean & SD & t & df & Sig(2-tailed) \\
\hline Experimental Group & 56 & 10.98 & .70 & .26 & 110 & .79 \\
Control Group & 56 & 10.94 & .72 & & & \\
\hline
\end{tabular}

Table 3 shows the post-test mean score of experimental group is 22.05 (SD $=1.63$ ) which is higher than the post-test mean score, $17.16(\mathrm{SD}=1.53)$ of control group. The difference between these two post-test means was significant $[\mathrm{t}(110)=16.33, \mathrm{p}<.05]$ in favour of the experimental group which revealed that the students' mathematics achievement of experimental group was significantly better than control group.

Table 3

Students' mathematics achievement post-test mean scores between experimental and control groups are compared using independent-sample t-test

\begin{tabular}{lllllll}
\hline Group & $\mathrm{n}$ & Mean & SD & t & df & Sig(2-tailed) \\
\hline Experimental Group & 56 & 22.05 & 1.63 & 16.33 & 110 & .00 \\
Control Group & 56 & 17.16 & 1.53 & & & \\
\hline
\end{tabular}

To identify the effects of Learning Together of group learning on students' attitudes toward mathematics, independent-sample t-test was also used to analyse pre-test and post-test mean scores of students in experimental and control groups. To check the assumption of normality of data for students' attitudes toward mathematics, pre-test and post-test scores were also recorded for each of the 112 students. The distribution had a skewness of -.38 for pre-test and skewness of -.01 for post-test. The distribution of pretest and post-test was considered normal due to its skewness between -1 and +1 (Morgan et al., 2001). The other check for normality using SPSS recommendation that skewness divided by standard error of skewness were -.65 and -.05 confirmed the normality (SPSS, 1999). As pre-test mean scores of experimental and control groups are described in Table 4, the mean score for the experimental group was $2.87(\mathrm{SD}=.71)$ and that of control group was $2.89(\mathrm{SD}=.75)$. The difference between students' attitudes toward mathematics pre-test mean scores of two groups [t $(110)=-.12, \mathrm{p}>.05]$ is not significant at .05 alpha level. This indicates that students' attitudes toward mathematics of both groups were similar at the beginning of this study.

Table 4

Students' attitudes toward mathematics pre-test mean scores between experimental and control groups are compared using independent-sample t-test

\begin{tabular}{lllllll}
\hline Group & $\mathrm{N}$ & Mean & $\mathrm{SD}$ & $\mathrm{t}$ & $\mathrm{df}$ & $\mathrm{Sig}$ (2-tailed) \\
\hline Experimental Group & 56 & 2.87 & .71 & -.12 & 110 & .89 \\
Control Group & 56 & 2.89 & .75 & & & \\
\hline
\end{tabular}

As shown in Table 5, the mean of the experimental group, $\mathrm{M}=4.46(\mathrm{SD}=.50)$ was greater than that of the control group, $\mathrm{M}=3.55(\mathrm{SD}=.50)$ which indicates a significant 
difference $[\mathrm{t}(110)=9.59, \mathrm{p}<.05]$ between these two post-test mean scores in favour of the experimental group that reveal that the experimental group showed improvement in students' attitudes toward mathematics in comparison to control group.

Table 5

Students' attitudes toward mathematics post-test mean scores between experimental and control groups are compared using independent-sample t-test

\begin{tabular}{lllllll}
\hline Group & $\mathrm{N}$ & Mean & SD & t & df & Sig(2-tailed) \\
\hline Experimental Group & 56 & 4.46 & .50 & 9.59 & 110 & .00 \\
Control Group & 56 & 3.55 & .50 & & & \\
\hline
\end{tabular}

To identify the teachers' perception on the implementation of Learning Together, the researcher conducted interview with two mathematics teachers who taught the experimental group of Learning Together. In order to address the ethical issues of preserving anonymity of the two participants and maintaining confidentiality of data, they were identified as Teacher 1 (T1) and Teacher 2 (T2) in the following report. The data which derived from the interview are discussed below:

The mathematics teachers in the experimental schools made comments on the students' characteristics that the students in the mathematics classrooms to be generally shy and inactive in the beginning of the experiment. According to them, the students were unwilling to talk. T1 pointed that the students were shy during the group activity. Below are the excerpts made by the teachers:

"... they were hesitate to speak" (T1). Because they did not facilitate each other's learning in the form of groups to solve their mathematical problems earlier.

“... they look inactive ... they don't understand" (T2). Because they are not given incentives to help each other's knowledge to achieve a shared goal under Learning Together condition earlier.

The mathematics teachers of experimental schools agreed that the students lacked confidence especially at the start of the Learning Together treatment. The experimental teachers, both of them, agreed that the condition was transitory. T1 said that once they are familiar with Learning Together of group learning “... they get confidence" (T1). Similarly, T2 agreed that "... after Learning Together introduction I found them active" (T2).

So although the students started with being shy at the beginning, they changed after they became familiar with Learning Together and had more confidence. The teachers commented that Learning Together of group learning contributed to the change of students' quality from being shy to become more confident students. Low-ability students faced problems in performing their tasks in mathematics. After being familiar with Learning Together they were able to overcome their problems. Below are the excerpts that described the teachers' comments.

"in the beginning they were unable to do..." (T1).

"...when they came in touch with Learning Together, it contributes to them to solve their problem..." (T2). 
Based on these statements, many of the students in the experimental group of this study had underachieved in their mathematics achievement. But when they were familiar with Learning Together of group learning and aware of their responsibility, they solved their mathematical problems.

The teachers' perception toward Learning Together of group learning was positive. When asked to comment on Learning Together, one of the teachers said that it was "I want Learning Together model of group learning to be implemented in secondary school context"(T1). This remark was positive. The following are the records from the interview as to teachers' perception on Learning Together:

"with Learning Together... students can contribute to ... can talk without feeling shy”(T2).

“... students improved their mathematics achievement”(T1).

“... students increased their attitudes toward mathematics"(T2).

\section{DISCUSSION}

This study was conducted to examine the effects of Learning Together model of group learning on students' mathematics achievement and attitudes toward mathematics along with an examination of teachers' perception on the implementation of Learning Together in selected secondary schools in Natore, Bangladesh. Findings from this study indicated that Learning Together had significant effects on students' mathematics achievement and attitudes toward mathematics. Students in the experimental group showed significant improvement in their mathematics achievement and attitudes toward mathematics in comparison to control group. The result suggests that the increase of the students' mathematics achievement and attitudes toward mathematics post-test mean scores for the experimental group was due to the significant effects of Learning Together treatment and its strong association with mathematical performance. In the Learning Together environment, students' groups were formed heterogeneously, ie, every group consisted of high-ability and low-ability students, and the better students were given incentives to help the weaker ones to solve their problems to achieve a shared achievement in mathematics. The students in the experimental group were kept under Learning Together condition in which they had the opportunity to help each other, share with each other and facilitate each other's learning to solve their mathematical problems, hence, a significant improvement on mathematical performance was obtained in this study. The findings of the study, therefore, were consistent with the results as reported by Ozsoy and Yildiz (2004) and Gokkurt et al. (2012). The researchers of both studies found that Learning Together of group learning strategy was more effective in comparison to traditional teaching in mathematics teaching and learning. The findings of this study were also consistent with studies by Barbato (2000), Effandi (2003) and Martin (2005). These studies found that the mathematical performance of group learning students had significantly better than traditional teaching students. The findings of the present study were similar to the findings of Tran's (2013) study who found group learning had a positive effect on mathematics achievement and attitudes toward mathematics. The results of present study were also similar to the studies of Zakaria et 
al. (2010) and Alabekee et al. (2015). They found that the experimental group using group learning had higher mathematics achievement than the control group of traditional teaching method. The findings of this research study were also in line with the findings of Gubbad (2010) who found group learning model was better than the traditional way of teaching in improving students' performance in mathematics.

Data generated from the interview illustrated that the teachers were very positive with their comments toward the implementation of Learning Together model of group learning in the mathematics classrooms. With Learning Together, students who were initially shy gained confidence to speak and improved their confidence in classrooms. The comments highlighted from the interview sessions showed that the implementation of Learning Together in the mathematics classrooms encouraged students to be supportive and had more ideas to share with their group members to solve their mathematical problems. The teachers commented that their students liked group activities and could speak without being shy when they worked together in the experimental group. The benefits that were described by the teachers were shared responsibility and helping one another. When the students worked in the experimental group, teachers found that they have more information to contribute to the group. They were always active to share their knowledge to their group members. Based on the interview, the teachers perceived that the elements of Learning Together model were well received by the students which contributed to the improvement of their mathematics achievement and attitudes toward mathematics.

\section{CONCLUSION}

Learning Together model of group learning had significant effects on students' mathematics achievement and attitudes toward mathematics, and the experimental teachers were positive in terms of their comments on the implementation of Learning Together in the mathematics classrooms. The findings revealed that the improvement of students' mathematics achievement and attitudes toward mathematics for the experimental group was due to the significant effects of the Learning Together treatment. It was found that students' mathematics achievement and attitudes mathematics were affected by exposure to the Learning Together in this research study. Students in the form of groups seemed to prefer to learn mathematics by sharing, helping, encouraging and facilitating each other's learning to reach a shared goal. The experimental teachers were of the same opinion with Learning Together model to be implemented in the secondary school context to improve students' mathematical performance. The findings based on the teachers' responses illustrated that Learning Together model was well received by both the students and the teachers, and Learning Together were effective in improving students' mathematical performance in the secondary mathematics classrooms. Therefore, Learning Together of group learning can successfully be implemented in secondary schools to promote students' mathematical performance in SSC examination, and education authorities in Bangladesh should encourage secondary teachers to practice Learning Together regularly and effectively, and teacher education institutions to make it part of their curriculum content. Finally, based on the findings and suggestions of this research study, future studies are 
encouraged on the importance of implementing Learning Together model in primary, secondary and tertiary levels by looking closer at the students' mathematical performance and teachers' perception in this study.

On the whole, Learning Together model of group learning contributed to the development of students' mathematical performance due to proper formation of groups, group members' cooperation to each other's learning and their sincerity to teachers' incentives during the treatment period, with this, this research study came to a conclusion that teachers' expertise on implementing Learning Together model can make our students mathematics loving and develop their interest in mathematics.

\section{ACKNOWLEDGEMENT}

The authors are very grateful to Director, Natore Institute of Education and Research, Natote, Bangladesh for conducting this research study and gratefully acknowledge the support from Dean of Faculty of Teacher Training and Education, University of Jember, Indonesia as well as from Head of Department of Post-Graduate Mathematics Education of Faculty of Teacher Training and Education, University of Jember, Indonesia.

\section{REFERENCES}

Alabekee, E. C., Samuel, A., \& Osaat, S. D. (2015). Effects of cooperative learning strategy on students' learning experience and achievement in mathematics. International Journal of Education Learning and Development, 3(4), 67-75.

Barbato, R. (2000). Policy implications of cooperative learning on the achievement and attitudes of secondary school mathematics students. Ph.D. Thesis, Fordham University, New York.

Berg, K., \& Latin, R. (1994). Essential of modern research methods. Englewood Cliffs, Prentice- Hall, Inc, NJ.

BISE (2014). Board summary of the secondary school certificate examination-2014. Ministry of Education, Dhaka, Bangladesh.

Campbell, D.T., \& Stanley, J.C. (1963). Experimental and quasi-experimental design for research. Rand Mcnally College Publishing Company, Chicago.

Cohen, L., Manion, L., \& Morrison, K. (2002). Research method in education. TJ International Ltd, Cornwall.

Effandi, Z. (2003). The effects of cooperative learning on students in a matriculation mathematics class. Ph.D. Thesis, Universiti Kebangsaan Malaysia, Bangi.

Fennema, E., \& Sherman, J.A. (1976). Fennema-Sherman mathematics attitude scales. Instruments designed to measure attitudes toward the learning of mathematics by males and females. JSAS Catalog of Selected Documents of Psychology, 6(31). (Ms. No. 1225).

Gokkurt, B., Dundar, S., Soylu, Y., \& Akgun, L. (2012). The effects of learning together technique which is based on cooperative learning on students' achievement in mathematics class. Procedia - Social and Behavioral Sciences, 46, 3431-3434. 
Gubbad, A. A. M. A. (2010). The effects of cooperative learning on the students' academic achievement and retention of the mathematics concepts at the primary school in Holy Makkah. Journal of King Saud University - Educational Sciences and Islamic Studies, 22(2), 13-23.

Hinton, P. R., Brownlow, C., McMurray, I., \& Cozens, B. (2004). SPSS explained. Routledge Inc, New York.

Hossain, A., Termizi, R. A., Aziz, Z., \& Nordin, N. (2013). Group learning effects and gender differences in mathematical performance. Croatian Journal of Education, 15(2), 41- 67.

Johnson, D. W., \& Johnson, R. T. (1994). Learning together and alone. Allyn and Bacon, London.

Leedy, P. D., \& Ormrod, J. E. (2001). Practical research planning and design. Merrill Prentice Hall, New Jersey.

Martin, R. L. (2005). Effects of cooperative and individual integrated learning system on attitudes and achievement in mathematics. Ph.D. Thesis, Florida International University, Florida.

Miles, M., \& Huberman, A. M. (1994). Qualitative data analysis. SAGE Publications, London.

Morgan, G. A., Griego, O. V., \& Gloeckner, G. W. (2001). SPSS for windows: an introduction to use and interpretation in research. Lawrence Erlbaum Associates, London.

Ozsoy, N., \& Yildiz, N. (2004). The effect of learning together technique of cooperative learning method on student achievement in mathematics teaching 7th class of primary school. Turkish Online Journal of Educational Technology, 3(3), 49-54.

Rimmerman, H. (2004). Resources in cooperative learning. San Clemente, Kagan Publishing, CA., USA.

Samad, M. A. (2005). Ganit shikkha-o-prashikkhon. Samad Publication and Research, Dhaka.

Sechrest, L., \& Sidani, S. (1995). Quantitative and qualitative methods: is there an alternative? SYSTEM, 18(1), 77-87.

SPSS, I. (1999). SPSS base 10.0 application guide. SPSS Inc, Chicago.

Tran, V. D. (2013). Effects of student teams achievement division (STAD) on academic achievement, and attitudes of grade $9^{\text {th }}$ secondary school students toward mathematics. International Journal of Science, 2, 1-15.

Zakaria, E., Chin, L. C., \& Yusoff, D. M. (2010). The effects of cooperative learning on students' mathematics achievement and attitudes towards mathematics. Journal of Social Science, 6(2), 272-275. 